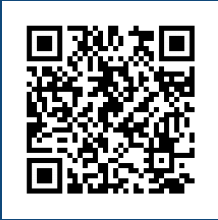

Keywords:

Non-destructive technique

Structural monitoring

Displacements

Historic:

Received 28/I I/2018

Accepted 08/03/2019

Correspondence: rodrigo.apereira@deg.ufla.br

Rodrigo Allan Pereiralat, Francisco Carlos Gomes ${ }^{\mathrm{lb}}$, Roberto Alves Braga Júnior ${ }^{\mathrm{lc}}$, Fernando Pujaico Rivera ${ }^{\text {Id }}$

\title{
DISPLACEMENT MEASUREMENT IN SAWN WOOD AND WOOD PANEL BEAMS USING PARTICLE IMAGE VELOCIMETRY
}

PEREIRA, R. A.; GOMES, F. C.; BRAGA JÚNIOR, R. A.; RIVERA, F. P. Displacement measurement in sawn wood and wood panel beams using particle image velocimetry. CERNE, v. 25, n. I, p. II0-II8, 2019.

\section{HIGHLIGHTS}

A methodology for measuring deformations using the PIV technique is proposed.

The PIV technique uses a comparison between two images to calculate the displacement.

The use of the PIV technique allows obtaining a deformation map of the material surface.

The PIV technique was effective in measurements compared to conventional methods

\section{ABSTRACT}

Throughout their useful life structures demand monitoring to verify their conditions of use. Thus, the need arises to seek methodologies capable to evaluate displacements and deformations in structural components of buildings. The objective of this research was to evaluate the use of the particle image velocimetry (PIV) technique to analyze test specimen behavior during a static bending test, additionally a displacement map is presented. The PIV technique measures variations of position of a region in an object from consecutive images from a loading session. The tests were performed on wood of Pinus oocarpa and Eucalyptus grandis, plywood panels, laminated veneer lumber (LVL) and oriented strand board (OSB). The results obtained by the PIV technique were compared to values obtained from dial indicators. It was verified that in all the materials tested, the PIV technique presented results similar to those found in the dial indicators. By means of the Student $t$ test, with a significance level of $1 \%$, some regions of analysis the values found by the PIV technique and the dial indicators were statistically similar. For the analyzed regions that did not achieve statistical equality, a correction equation was calculated ( $R^{2}$ higher than 0.99$)$. It was concluded that the PIV technique, with properly adjusted setup, presented results similar to those obtained in the conventional tests, proving its accuracy and reliability in displacement measurements, with the advantage of being a non-destructive and contactless structure monitoring technique. 


\section{INTRODUCTION}

The maintenance, verification and analysis of materials under load are essential for the proper use of the structural parts in the construction systems. The methodologies and techniques currently used for measurements of deformations in structural parts are, in general, complex, having high operational and equipment costs and demands physical contact with structures that may be fixed in a difficult access area. Therefore, the study and the use of new test techniques capable of measuring deformations becomes a good alternative to overcome the difficulties encountered in the field of structural maintenance.

For the verification of the mechanical behavior of materials submitted to different types of efforts, the most used techniques are those denominated as conventional. The universal test machine (UTM) is often employed in this type of test, for its precise results and established and standardized methodology.

However, the problem with conventional analyses is related, not only to the delay in results, high number of samples needed, and consequently high operational cost (Gouvêa et al., 20I I), but also to the restriction of using the UTM in the field.

The equipment and techniques required to verify the mechanical behavior of specimens of a given material are different from those required for analysis of a structural part. Thus, it becomes impracticable to use conventional testing techniques that require robust and difficult to install machines in the field.

In this sense, several test techniques are used to measure the conditions of use, characteristics, and properties of the materials used in buildings. Oliveira et al (2015) verified a correlation between the results of the non-destructive test techniques and the wood properties. The same author states that among the non-destructive techniques, those most used for the evaluation of wood material are chemical analysis, X-rays, vibrational techniques, and sound wave transmission.

According to De Paula et al. (2016), the increase in the use of non-destructive test techniques is due to the reliability of their results, speed in the tests, and subsequent continued use of the analyzed materials.

Among the non-destructive test techniques, the particle image velocimetry (PIV) technique stands out. This is an optical technique that generates results from sequential image analysis. The PIV technique was originally used in the field of fluids and gases (Bangalee et al., 20I3; Xu et al., 2017) and in recent years it has also been applied to measurements of solid bodies (Baba and
Peth, 20I2; Braga Jr. et al., 20I5; Magalhães et al., 20I5; Pereira, 20I4; Souza et al., 20I4; Pereira et al., 2018).

According to Adrian and Westerweel (20II), the Particle Image Velocimetry (PIV) is an optical technique designed originally to flow visualization in $2 \mathrm{D}$ or $3 \mathrm{D}$. In this method it is necessary that the study flow contain some types of particles, in other words, visible elements, markers or patterns in the flow. Therefore, a set of pictures over time are taken of the particles in the flow or object under study where the particle positions are obtained. In this sense the particles are tracked among/between images, forming a time-space data array and consequently a velocity flow map with magnitude and direction is obtained.

It is possible use many methods to recognize a particle or set of particles between two consecutive images, the most widely used method is the Pearson coefficient correlation (PCC) method. In this analysis method, pixel regions with particles are selected in each pair of images and if the PCC value, calculated between these regions, exceeds a defined PCC value, the correlation is declared as positive, otherwise, another analysis region in the last image is selected and the match test is performed again (Adrian and Westerweel, 20l I).

The advantages of the PIV technique in relation to conventional test techniques are the collection and automatic data analysis speed, technique field application facility, low cost equipment and no damage to the material under study. Regarding optical techniques, the advantage of the PIV technique is that it can be applied to any material and surface, since the use of marker points minimizes measurement errors and significantly avoids obtaining false positives.

One of the most used materials in building structures lumber and reconstituted wood panels. However, because it is an anisotropic material, unlike isotropic materials such as steel and concrete, it has greater mechanical behavior complexity, making it difficult to evaluate accurately and reliably. In this context it is essential to search for new test methodologies that comply with standardized recommendations.

The objective of this work was to evaluate the performance of the PIV technique when applied to displacement measurements in lumber (Eucalyptus grandis and Pinus oocarpa) and wood panels (Plywood, LVL and OSB) in a static bending test, using manually painted particles.

\section{MATERIAL AND METHODS}

Static bending tests were carried out in the Universal Testing Machine (AROTEC ${ }^{\circledR}$ ) with a load capacity of $300 \mathrm{kN}$. 
The following materials were used for the tests: wood samples from the species Pinus oocarpa and Eucalyptus grandis as well as LVL Panels, Plywood Panels and OSB panels (Table I).

TABLE I Number of specimens for each tested material.

\begin{tabular}{cc}
\hline Material & \# OF SPECIMENS \\
\hline Pinus oocarpa & 23 \\
Eucalyptus grandis & 23 \\
LVL Panels & 30 \\
Plywood Panels & 30 \\
OSB Panels & 25 \\
\hline
\end{tabular}

Samples were manufactured in accordance with international standards for the preparation of test specimens (American Society for Testing and Materials standard (1994) ASTM DI43-94 and Normen für Holzfaserplaten Spanplatten Sperrholz (1982) DIN 52362.)

In the tests a professional digital camera CANON EOS Rebel t3, set of lenses for focus adjustment and zoom, thin tip black pen and the Universal Testing Machine were used.

Pinus oocarpa and Eucalyptus grandis lumber samples

The wood specimens of Pinus oocarpa and Eucalyptus grandis were obtained from trees of experimental forest plantations located on the Campus of the Federal University of Lavras - UFLA, in the city of Lavras, Minas Gerais, Brazil.

The samples for the static bending tests were cut with circular saw blade according to ASTM DI4394 (American society for testing and materials - ASTM, 1994), with dimensions of $0.025 \times 0.025 \times 0.41 \mathrm{~m}$. Static bending tests followed the American Society for Testing and Materials standard (1994) ASTM DI43-94.

\section{Panel specimens - Oriented Strand Board - OSB}

The purchased OSB panels were produced with phenol-formaldehyde adhesive, density of $650 \mathrm{~kg} . \mathrm{m}-3$ and dimensions of $2.44 \times 1.22 \times 0.015 \mathrm{~m}$ (Length, width and thickness).

The static bending test specimens were made using a circular saw, as described by the American Society for Testing and Materials standard (2006) ASTM DI037 and Normen für Holzfaserplaten Spanplatten Sperrholz (1982) DIN 52362 with the dimensions of $0.25 \times 0.05 \times$ $0.15 \mathrm{~m}$ (Length, width and thickness). Specimens were subsequently air-conditioned at $22 \pm 2{ }^{\circ} \mathrm{C}$ and $65 \pm 5 \%$ relative humidity before the tests.

\section{Panel specimens - Plywood and LVL}

The wood used to make the plywood and LVL panels in this work was 25-year-old Pinus oocarpa. The logs were peeled and heated in water at a temperature of $65^{\circ} \mathrm{C}$ during 24 hours. Through the use of a laminating lathe the logs were processed, thus obtaining blades with a thickness of $2.00 \mathrm{~mm}$. The blades were then slit in $0.55 \times 0.55 \mathrm{~m}$ dimensions and oven dried at $60^{\circ} \mathrm{C}$ until moisture content between 5 and $6 \%$ was obtained.

Previous to the manufacturing stage of the plywood and LVL, the already dried slabs were classified according to decreasing quality (A, B, C, D), according to the Brazilian Standard NBR 953I - Plywood Sheets: Classification of the Brazilian Association of Technical Standards - ABNT (1986). In the present study, only the blades with $B$ classification were used, both for the covers and for the core of the panels.

The panels were produced with phenolformaldehyde adhesive, the panels being cleared with seven layers crossed with each other and the LVL panels with seven layers positioned in the same direction.

The static bending test specimens of plywood and LVL were made using a circular saw, according to European Commission for Standardization (1993) EN 310 , and later were air-conditioned at $\left(22 \pm 2^{\circ} \mathrm{C}\right)$ and relative humidity of $(65 \pm 5 \%)$.

Assays with the PIV technique and validation using UTM

The procedures for performing the tests using the PIV technique using the Eucalyptus grandis test specimens, Pinus oocarpa, in static bending tests were in accordance with ASTM DI43 (ASTM, 1994). The plywood and LVL test bodies followed the European committee for standardization (1993) EN 310 and OSB panels according to the American society for testing and materials (2006) ASTM DI 037.

Initially, the static bending test apparatus of the Universal Testing Machine was fitted with dial indicators (one at the center of the sample and two at half the distance between the supports and the point of application of the load) for measuring the displacement values of the beams. A professional digital camera (CANON EOS Rebel $\mathrm{t} 3$ ) was positioned perpendicular to the sample surface ( $0.25 \mathrm{~m}$ away) for image capturing. The camera was equipped with a set of lenses to better adjust the focus to the surface of the specimen. The capturing of the images occurred with the use of a remote control to avoid any camera disturbance. Considering that the specimens were made with exact dimensions and the application of the load occurred exactly in the center of gravity of the cross section, it is understood that no deformation occurred out of the plane of the camera. 
Thus, it was possible determine the vertical deformation of the specimens subjected to static bending test in the plane. The equipment used, the test specimens, and the instrumentation of the universal test machine are shown in Figure I.

a.

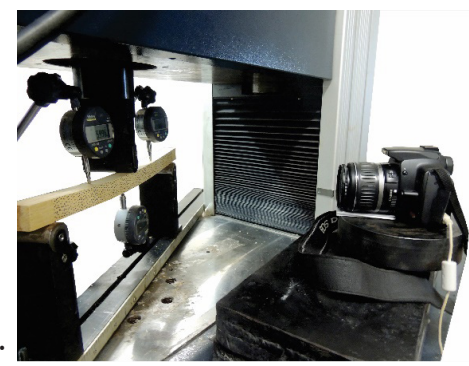

b.

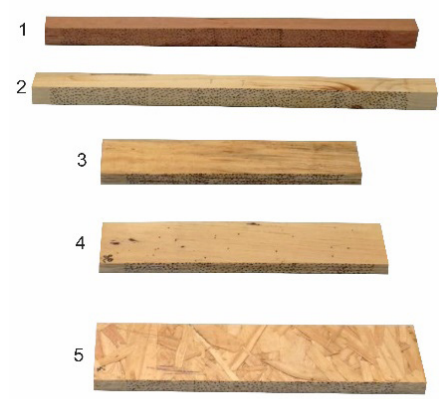

FIGURE I General view of the Universal Testing Machine, the instrumentation of the static bending test for the application of the PIV technique and the materials tested. (a) Overview of the Universal Testing Machine and the instrumentation of the static bending test for the application of the PIV technique. (b) Specimens used in the experiment: I- Pinus oocarpa lumber; 2Eucalyptus grandis lumber; 3 - LVL Panel; 4 - Plywood panel; 5 - OSB Panel.

Prior to the capture of the images, the surface of all the specimens was marked with points made with a fine-tipped marker pen. The points were distributed throughout the surface of the specimens with a density of 9.4 points per $\mathrm{cm}^{-2}$. The mean diameter of the points was $0.0015 \mathrm{~m}$, according to Figure 2 .

An alternative to marking the points with ink is the use of the natural characteristics of the surface of

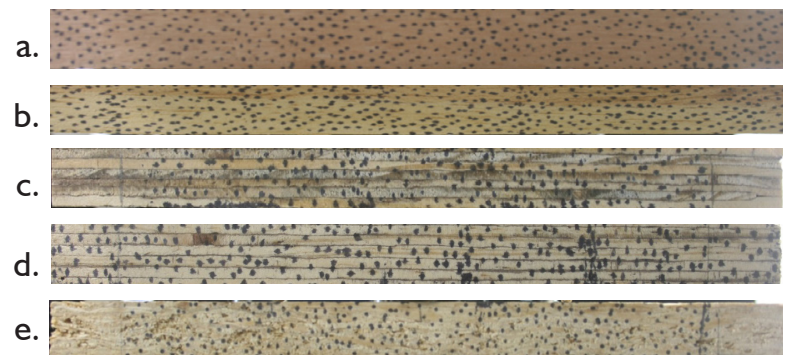

FIGURE 2 Markers inserted on the surface of the tested materials. Proofs with markers painted with marker pen and random pattern. (a) Eucalyptus grandis. (b) Pinus oocarpa. (c) Plywood panel. (d) LVL Panel. (e) OSB Panel. the materials being studied. This situation applies to materials that do not have a solid color surface, without any differentiation in pigmentation.

The images were captured during static bending tests at a regular time interval. For the test specimens of Eucalyptus grandis and Pinus oocarpa the interval between images was 30 seconds and for the LVL, plywood, and OSB panels the interval between images was 5 seconds.

Considering that on average the static bending tests for Eucalyptus grandis and Pinus oocarpa specimens had a duration of approximately 600 seconds (loading speed of $1.3 \mathrm{~mm} \cdot \mathrm{min}^{-1}$ ) and that the duration of the tests with the bodies of LVL, OSB, and plywood panels were around 90 seconds (loading speed of $5 \mathrm{~mm} \cdot \mathrm{min}^{-1}$ ), each specimen was imaged from 18 to 20 times, enough to verify the behavior of these materials by the PIV technique under a load situation.

For the application of the PIV technique, the first image was captured before loading began $(t=0, d=0)$ and the others were captured according to the pre-established time interval. Thus, the first image $(t=0, d=0)$ serves as a comparison parameter for subsequent images.

After completion of the tests, the captured images were duly processed in image processing software (Image J) in which the images were converted to the 8 bit format and the number of pixels of the images was reduced to $25 \%$ of the original in order to reduce image size. This procedure is important in order to enable the processing of these images through the PIV algorithm in the GNU Octave free software. For the processing of the PIV technique a $32 \times 32$ pixel interrogation window, I pixel step size, search arm around the analysis region of 50 pixels and similarity threshold was used for correlation of the interrogation windows of 0.82 . The choice of $32 \times 32$ pixel interrogation windows size occurred due to the fact that a small interrogation window size, $8 \times 8$ pixels for example, usually generates a higher probability of occurrence of false positives due to the small amount of marker points found in its area. On the other hand, large interrogation windows $(64 \times 64$ pixels) present problems in relation to their angular displacement and also with the image processing time. Therefore an intermediate interrogation window size was chosen ( $32 \times 32$ pixels).

\section{Image Processing}

After the images were processed in the PIV algorithm, graphs were obtained with the deformations referring to the sites chosen for analysis (Pereira et al., 20I8). In this case, the chosen regions were those close to the three positioned dial indicators (left, center and right).

Using the values of the PIV deformation graphs and the values obtained by reading the dial indicators, it 
was possible to compare these results with each of other all test specimens tested.

For the analysis of the results, linear regressions were made for the three regions analyzed in all test specimens. These regressions occurred with the positioning of the values obtained by the PIV technique in the graphs on the $x$ axis and the values of the dial indicators on the $y$ axis.

An advantage of regression is the use of Student $t$ test for significance of the parameters, thus verifing if one variable is equal to the other and, if it is not, the generated equations are also correction equations, since that from the deformation values by the PIV technique (x-axis), the corrected value corresponds to those found in the conventional test ( $y$-axis).

\section{Statistical method}

In order to statistically compare the deformation presented by the PIV technique with the values of the conventional test, the equations generated in the previously established regressions were analyzed.

The statistical procedure was delineated with the listing of all the linear regression equations performed in the three regions of analysis in all test specimens. Therefore, each analyzed region presented an equation of the type " $y$ $=\mathrm{ax}+\mathrm{b}$ ", it being possible to obtain a correction equation for each region of analysis for each material.

At the end of the procedure, it was assessed whether the values found by the PIV technique and those of the conventional assay were statistically the same or different. For that, the Student $t$ test was applied.

To verify if the values measured by the dial indicators and the PIV technique were statistically the same, the mean equations obtained through the regressions were used.

Based on the assumption that to be exactly the same the mean regression equations would need to be " $y=x$ ", two hypotheses were formulated:

$\int \mathrm{H}_{0}: \mathrm{a}=1$

$\left\{\mathrm{H}_{1}: \mathrm{a} \neq 1\right.$

$$
\left\{\mathrm{H}_{0}: \mathrm{b}=0\right.
$$$$
\left\{\mathrm{H}_{1}: \mathrm{b} \neq 0\right.
$$

Thus, the Student $\mathrm{t}$ test was applied with significance level of $1 \%$, to determine the acceptance or rejection of the hypotheses $\mathrm{H}_{0}$. In case of acceptance of $\mathrm{H}_{0}$ in both tests, no correction need be configured, that is, $y=x$. If the hypothesis $\mathrm{H}_{0}: \mathrm{a}=\mathrm{I}$ is accepted and the hypothesis $\mathrm{H}_{0}: \mathrm{b}=0$ is rejected, the correction equation would be $y=x+b$. In situations of rejection of the hypothesis $\mathrm{H}_{0}: \mathrm{a}=\mathrm{I}$ and acceptance of the hypothesis $\mathrm{H}_{0}: \mathrm{b}$ $=0$ the correction equation becomes $y=a x$. Rejecting the two hypotheses $\left(\mathrm{H}_{0}: \mathrm{a}=\mathrm{I}\right.$ and $\left.\mathrm{H}_{0}: \mathrm{b}=0\right)$ the correction equation was the estimated equation itself, $y=a x+b$.

\section{RESULTS AND DISCUSSION}

The images were processed using a PIV algorithm, aiming to find the displacements of an interrogation window positioned in the reference image compared to the subsequent images, according to Figure 3.

The sequence of images observed in Figure 3 indicates that, from the beginning to the end of the assay, the interrogation windows assumed locations consistent with the deformation verified on the specimen, that is, there was no loss of correlation in any of the regions of analysis, with the rupture being presented in Figure 3 (d).

In a similar situation, Pereira (20I4) observed that close to or after the sample rupture, the PIV technique, associated with the sunset laser, presented a total loss

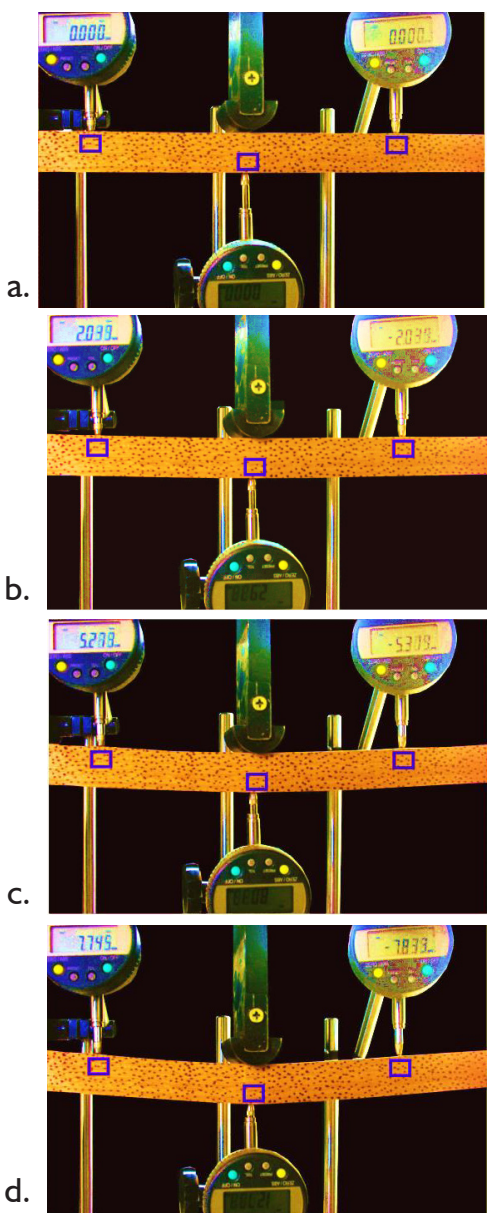

FIGURE 3 Displacement of interrogation windows during the tests. (a) time zero and load $0 \mathrm{kN}$. (b) time 150 seconds and load $0.8172 \mathrm{kN}$. (c) time 360 seconds and load $2.2524 \mathrm{kN}$. (d) time 540 seconds and load $2.4228 \mathrm{kN}$. 
of correlation, thus not compromising the responses for larger deformations. Pereira (20I4) also verified that the PIV technique could be applied effectively only in the elastic region of materials in the loading phase, with very small deformations. The same occurred in the work of Souza et al. (2014).

Pereira (2014) also verified that the application of the PIV technique associated with the sunset laser presents great difficulty in maintaining an adequate test configuration, since the particles (markers) generated by the sunset laser were different in relation to quality and quantity in each sample, impairing an adequate evaluation of the results among the specimens. This fact did not occur in this work, mainly due to an adequate choice of markers and their distribution pattern on the surface of the specimens.

The PIV technique presents, in addition to the displacement occurring at one point, the map of displacements on the surface of the object under loading (Figure 4).

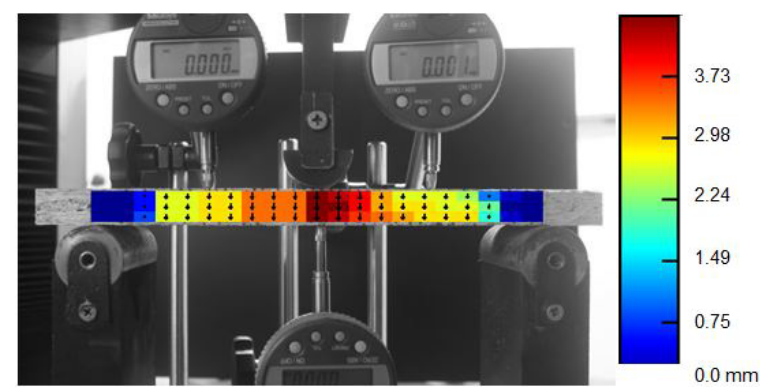

FIGURE 4 Map of deformations in OSB panel specimen.

The mapping of the displacements occurring throughout the analyzed surface (Figure 4) allows the analysis of points with higher and lower displacements, besides the identification of regions with higher probability of rupture or presence of areas with less resistance. This type of result can be considered an advantage of the PIV technique in relation to other optical techniques, since the marker points allow the creation of tracking regions between consecutive images, and in particular to Digital Image Correlation (DIC), the main difference is the vector map that can indicate the level of displacements associated to their direction, that can be seen superposed (DIC and PIV) in Figure 4.

\section{Comparison between conventional and PIV technique}

The application of the PIV technique in the test specimens occurred concomitantly with the mechanical tests of static bending to validate the outcomes. As such, it was possible to compare the deformations by the conventional method and the PIV technique. Considering the values of the dial indicators as the base values, that is, the actual deformation value, these results were compared with those obtained by means of the PIV technique (Figure 5).

Through the analysis of the graphs contained in Figure 5, it can be observed that in all the materials tested the values found by both methodologies followed the same line with small variations, even in situations of material rupture.

The graphs in Figure 5 show the effectiveness of the PIV technique in measuring any type of deformation,

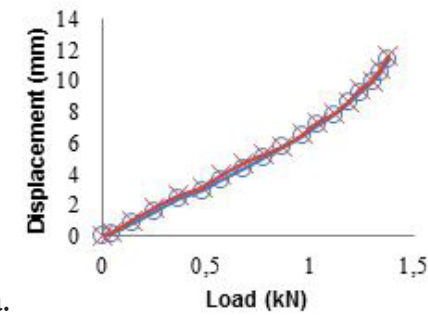

a.

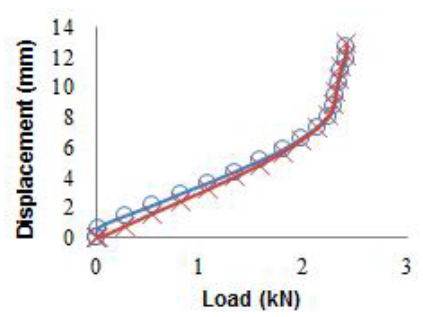

b.
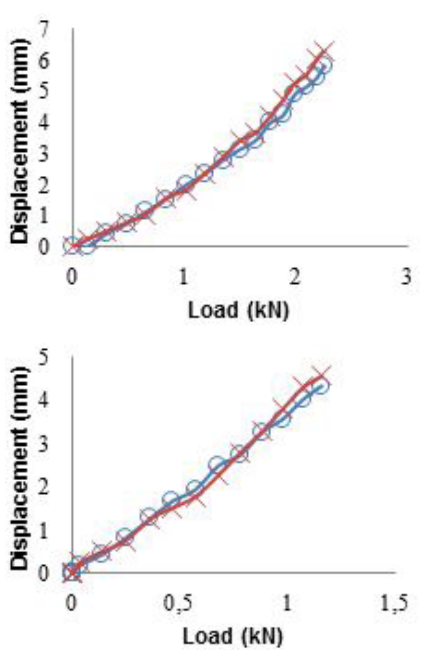

d.

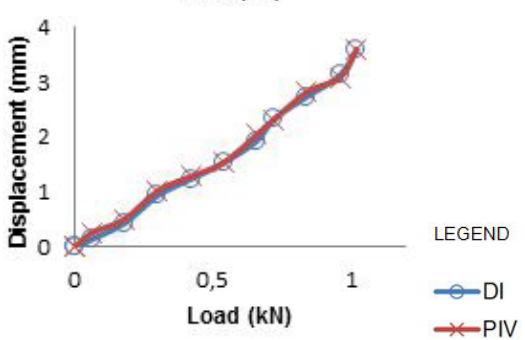

FIGURE 5 Comparison of the displacement values obtained by the use of PIV technique and the dial indicators (DI). (a) Pinus oocarpa test specimen. (b) Eucalyptus grandis test specimen. (c) Plywood panel specimen. (d) LVL panel specimen. (e) OSB panel specimen. 
since in previous studies (Braga Jr. et al., 2015, Pereira, 2014 , Souza et al., 20I4) it was verified that the accuracy of this technique was restricted to small deformations.

It is noteworthy that these materials present different mechanical behaviors. Another important fact is the static bending tests, being specific for each type of material (lumber and panels), varying the dimensions of the specimens, distance between supports and the load application rate.

\section{Statistical analysis}

From the comparison of the results obtained by the conventional method (dial indicators) and the PIV technique, a statistical verification of the values found by the two methodologies was envisaged.

For this statistical analysis, the parameters "a" and " $b$ " of the linear regression equations $(y=a x+b)$ developed in all the specimens with the displacement values were used by the PIV technique (x-axis) and by the conventional analysis ( $y$-axis).

The linear regressions of all test specimens presented a correction equation with values of "a" and "b" very close to I and 0 , respectively (Figure 6), an ideal condition for equality between methodologies. In addition, $\mathrm{R}^{2}$ values were always higher than 0.97 , indicating a high correlation value between the two sets of values.
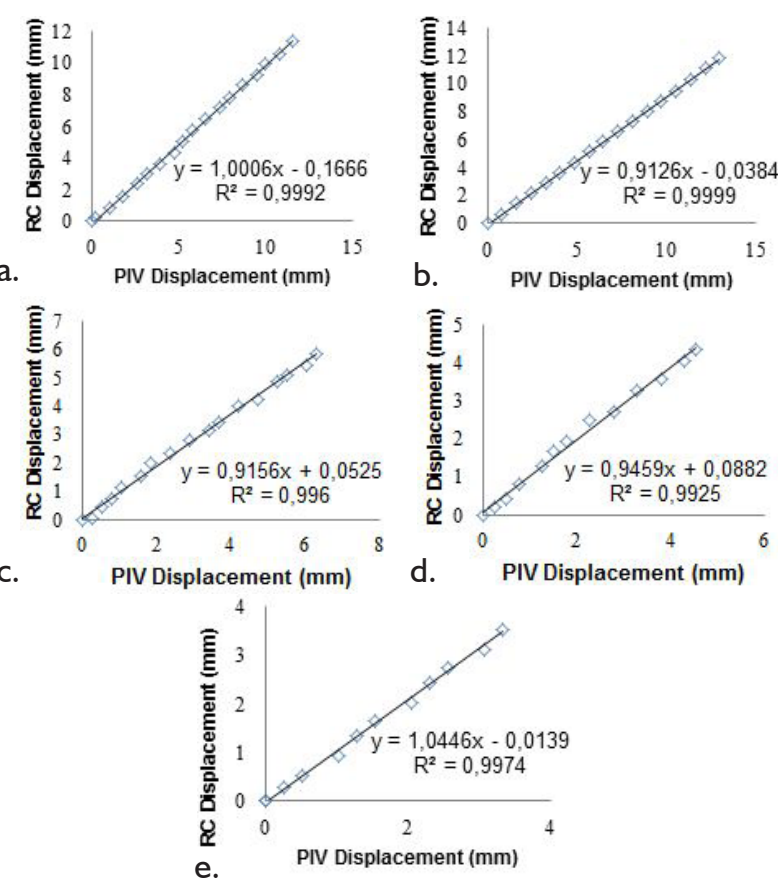

FIGURE 6 Linear regression of the displacement values obtained by the PIV technique ( $x$-axis) and the dial indicators (y-axis). (a) Pinus oocarpa test specimen. (b) Eucalyptus grandis test specimen. (c) Plywood panel specimen. (d) LVL panel specimen. (e) OSB panel specimen.
As observed in Figure 6, each specimen of each material was subjected to a linear regression analysis, thus generating a correction equation in the " $y=a x+$ b" configuration and a coefficient of determination $\mathrm{R}^{2}$.

In this way, it was possible to analyze each region of analysis (left, center and right) separately in each test specimen and later for each specific material, being represented by a mean correction equation, from the mean values of "a" and "b" of each specimen tested, as shown in Table 2.

Based on the mean equations in Table 2, the statistical analysis was performed comparing the conventional technique and the PIV technique. Applying the t-Student test with a significance level of $1 \%$, it was observed (Table 3 ) that in some cases the previously described hypotheses $\mathrm{H}_{0}$, was accepted and in other cases rejected.

The results of the applied statistical analysis show that even the materials and regions and samples that had the hypotheses totally or partially rejected presented a correction equation with very small values, that is, correction values "a" very close to I and correction values "b" close to zero.

Furthermore the lumber materials (Pinus oocarpa and Eucalyptus grandis) had their statistical hypotheses accepted for the central region of the specimens. This fact can be explained by their different mechanical behavior regarding the panels, since in the tests a less brittle deformation pattern occurred for this type of material.

It was also observed that the hypotheses of the central region of analysis were accepted, indicating that the PIV technique provides better responses in regions with more elastic deformation (central part) and with lower surface rotation, a characteristic frequently encountered in regions far from the central region of the specimen.

The wood panels (LVL, Plywood and OSB) also presented analysis regions with accepted hypotheses, with LVL being the panel type with the best PIV results. However, the regions of analysis with rejection of the hypotheses were more frequent, which may be justified by isolated ruptures in one or more blades or chips that constitute these materials.

\section{CONCLUSION}

With the present study it was concluded that the PIV technique is an accurate and effective tool for the measurement of deformations occurring in materials under load. This was proven by comparing the results of the PIV technique with those of conventional analysis traditionally used and standardized. 
TABLE 2 Average correction equations for each type of material.

\begin{tabular}{|c|c|c|c|}
\hline \multicolumn{4}{|c|}{ Mean equations from Linear Regression } \\
\hline Materials & Left & Center & Right \\
\hline Eucalyptus grandis & $y=0.947 x-0.066$ & $y=1.019 x-0.054$ & $y=0.984 x-0.129$ \\
\hline Pinus oocarpa & $y=0.873 x+0.044$ & $y=|.03| x+0.06 \mid$ & $y=0.939 x-0.023$ \\
\hline Plywood & $y=0.953 x+0.094$ & $y=1.188 x+0.126$ & $y=0.912 x+0.050$ \\
\hline LVL & $y=1.006 x+0.045$ & $y=1.115 x+0.035$ & $y=0.982 x+0.044$ \\
\hline OSB & $y=0.965 x+0.040$ & $y=1.113 x+0.0008$ & $y=0.919 x+0.031$ \\
\hline
\end{tabular}

TABLE 3 Statistical analysis of the results by the dial indicators and the PIV technique in the three regions of analysis.

\begin{tabular}{|c|c|c|c|c|c|c|c|c|c|c|}
\hline \multirow[t]{2}{*}{ Material } & \multirow{2}{*}{$\begin{array}{l}\text { Analysis } \\
\text { Region }\end{array}$} & \multicolumn{2}{|c|}{$\begin{array}{c}\text { Mean } \\
\text { Equation }\end{array}$} & \multirow{2}{*}{$\begin{array}{c}\text { Mean } \\
\mathrm{R}^{2}\end{array}$} & \multicolumn{2}{|c|}{$\mathrm{t}_{\text {calc } 0,005, \mathrm{n}-1}$} & \multirow[t]{2}{*}{$\mathrm{t}_{\mathrm{tab} 0,005, \mathrm{n-1}}$} & \multicolumn{2}{|c|}{$\mathrm{H}_{0}$} & \multirow[t]{2}{*}{ Correction Equation } \\
\hline & & $\mathrm{a}$ & $\mathrm{b}$ & & $a$ & b & & $a=1$ & $b=0$ & \\
\hline \multirow{3}{*}{ Eucalyptus grandis } & Left & 0.947 & -0.066 & 0.992 & -1.880 & -1.408 & \multirow{3}{*}{2.819} & $\mathrm{~A}^{*}$ & $\mathrm{~A}$ & $y=x$ \\
\hline & Center & 1.020 & -0.055 & 0.999 & 1.008 & -1.518 & & A & A & $y=x$ \\
\hline & Right & 0.985 & -0.130 & 0.991 & -0.639 & -2.802 & & A & A & $y=x$ \\
\hline \multirow{3}{*}{ Pinus oocarpa } & Left & 0.874 & 0.044 & 0.998 & -10.428 & 1.088 & \multirow{3}{*}{2.819} & $\mathrm{R}^{* * *}$ & $A$ & $y=0.874 x$ \\
\hline & Center & 1.031 & $0.06 \mathrm{I}$ & 0.999 & 1.394 & 1.325 & & A & A & $y=x$ \\
\hline & Right & 0.940 & -0.024 & 0.995 & -3.213 & -0.505 & & & A & $y=0.940 x$ \\
\hline \multirow{3}{*}{ Plywood } & Left & 0.954 & 0.094 & 0.997 & -7.120 & 3.516 & \multirow{3}{*}{2.756} & $\mathrm{R}$ & $\mathrm{R}$ & $y=0.954 x+0.094$ \\
\hline & Center & 1.188 & 0.126 & 0.993 & 0.713 & 4.953 & & A & $\mathrm{R}$ & $y=x+0.126$ \\
\hline & Right & 0.913 & 0.050 & 0.997 & -2.833 & 3.124 & & $\mathrm{R}$ & $\mathrm{R}$ & $y=0.913 x+0.050$ \\
\hline \multirow{3}{*}{ LVL } & Left & 1.007 & 0.045 & 0.997 & 0.850 & 2.497 & \multirow{3}{*}{2.756} & $\mathrm{~A}$ & $\mathrm{~A}$ & $y=x$ \\
\hline & Center & 1.116 & 0.035 & 0.993 & 3.766 & 1.140 & & $\mathrm{R}$ & A & $y=1.116 x$ \\
\hline & Right & 0.982 & 0.044 & 0.997 & -2.069 & 2.000 & & A & A & $y=x$ \\
\hline \multirow{3}{*}{ OSB } & Left & 0.966 & 0.040 & 0.994 & -1.977 & 3.091 & \multirow{3}{*}{2.797} & A & $\mathrm{R}$ & $y=x+0.040$ \\
\hline & Center & 1.113 & 0.001 & 0.993 & 4.326 & 0.044 & & $\mathrm{R}$ & A & $y=1.113 x$ \\
\hline & & 0.920 & 0.032 & 0.995 & -8.106 & 2.730 & & $\mathrm{R}$ & A & $y=0.920 x$ \\
\hline
\end{tabular}

It was also concluded that with the use of manually painted particles on the surface of the specimens, the PIV technique could measure the deformations during the loading stages, with adequate results in small, medium and large deformations.

Eucalyptus grandis and Pinus oocarpa lumber, obtained better results with the application of the PIV technique due to its more elastic mechanical behavior than the mechanical behavior observed in the plywood, LVL and OSB panels.

\section{AKNOWLEDGEMENTS}

The authors thank CAPES, CNPq and FAPEMIG for their financial support for this research.

\section{REFERENCES}

ADRIAN, R. J.; WESTERWEEL, J. Particle image velocimetry. Cambridge University Press, 20I I. 558p.

AMERICAN SOCIETY FOR TESTING AND MATERIALS. Standard methods of evaluating properties of wood-base fiber and particles materials. Philadelphia, PA: ASTM D-I037, 2006.

AMERICAN SOCIETY FOR TESTING AND MATERIALS. Standard methods of testing small clear specimens of timber. Philadelphia, PA: ASTM D-143, 1994.

ASSOCIAÇÃO BRASILEIRA DE NORMAS TÉCNICAS. Chapas de madeira compensada: classificação. Rio de Janeiro, RJ: NBR 953I, 1986.

BABA, H. O.; PETH, S. Large scale soil box test to investigate soil deformation and creep movement on slopes by Particle Image Velocimetry (PIV). Soil and Tillage Research, v. I25, p.38-43, 2012.
BANGALEE, M. Z. I.; MIAU, J. J.; LIN, S. Y.; YANG, J. H. Flow visualization, PIV measurement and CFD calculation for fluid-driven natural cross-ventilation in a scale model. Energy and Buildings, v.66, p.306-3।4, 2013.

BRAGA JR, R. A.; MAGALHAES, R. R.; MELO, R. P.; GOMES, J. $V$. Maps of deformations in a cantilever beam using particle image velocimetry (PIV) and speckle patterns. Rem: Revista Escola de Minas, v.68, n.3, p.273-278, 2015.

DE PAULA, M. H.; DE MESQUITA, R. R. S.; GONÇALEZ, J. C.; RIBEIRO, E. S.; SOUZA, R. S. Utilização de métodos não destrutivos para caracterização simplificada da madeira de cumaru (Dipteryx odorata Willd). Biodiversidade, v. I5, n.2, 2016.

EUROPEAN COMMITTEE FOR STANDARDIZATION. Wood based panels - determination of modulus of elasticity and modulus of rupture in static bending. Brussels: EN 310, 1993.

GOUVÊA, A. D. F. G.; TRUGILHO, P. F.; COLODETTE, J. L.; BIANCHI, M. L.; SORAGI, L. D. C.; OLIVEIRA, A. C. Relação entre características da madeira da polpa celulósica de Eucalyptus com métodos não destrutivos na árvore viva. Scientia Forestalis, v.39, n.90, p. 205-220, 20 I I.

MAGALHAES, R. R., BRAGA, R. A.; BARBOSA, B. H. G. Young' $s$ Modulus evaluation using Particle Image Velocimetry and Finite Element Inverse Analysis. Optics and Lasers in Engineering, v.70, p.33-37, 2015.

NORMEN FÜR HOLZFASERPLATEN SPANPLATTEN SPERRHOLZ. Testing of wood chipboards bending test, determination of bending strength. Berlin: DIN 52362, 1982.

OLIVEIRA, M., SOUSA, H. S., BRANCO, J. M.; LOURENÇO, P. B. Análise comparativa do desempenho de ultrassons na avaliação não destrutiva da madeira de Castanho. Revista Portuguesa de Engenharia de Estruturas, v.2, n.14, p.3I-43, 2015. 
PEREIRA, R. A. Análise de esforços de flexão estática em madeira (Pinus Taeda) pelo método de velocimetria por imagem de partículas. 20|4. Dissertação de mestrado. Brazil: Universidade Federal de Lavras, Lavras, 2014.

PEREIRA, R.A, GOMES, F.C, BRAGA JUNIOR, R. A, RIVERA, F. P. Analysis of elasticity in woods submitted to the static bending test using the particle image velocimetry (PIV) technique. Engenharia Agrícola, v. 38, n. 2, p.159-165, 2018.
SOUZA, T. M., CONTADO, E. W., BRAGA, R. A., BARBOSA, H. C.; LIMA, J. T. Non-destructive technology associating PIV and Sunset laser to create wood deformation maps and predict failure. Biosystems engineering, v. 126, p. 109-1 16, 2014.

XU, S.; HUANG, S.; HUANG, R.; WEI, W.; CHENG, X.; MA, Y.; ZHANG, Y. Estimation of turbulence characteristics from PIV in a high-pressure fan-stirred constant volume combustion chamber. Applied Thermal Engineering, v. I I0, p.346-355, 2017. 